\title{
Violências nas trajetórias afetivo-sexuais de jovens gays: "novas" configurações e "velhos" desafios
}

\author{
Violence in the affective-sexual trajectories of young gay men: \\ "new" settings and "old" challenges
}

Wendell Ferrari (https://orcid.org/0000-0002-4597-5309) ${ }^{1}$

Marcos Antonio Ferreira do Nascimento (https://orcid.org/0000-0002-3363-4232) ${ }^{1}$

Conceição Nogueira (https://orcid.org/0000-0002-9152-754X) ${ }^{2}$

Liliana Rodrigues (http://orcid.org/0000-0001-6900-9634) ${ }^{2}$

${ }^{1}$ Programa de PósGraduação em Saúde da Criança e da Mulher, Instituto Fernandes Figueira, Fundação Oswaldo Cruz. Av. Rui Barbosa 716, Flamengo. 22250-020 Rio de Janeiro RJ Brasil. wendellferraripsi@ gmail.com

${ }^{2}$ Faculdade de Psicologia e Ciências da Educação, Universidade do Porto. Porto Portugal.

\begin{abstract}
This paper discusses the phenomenon of violence in the affective-sexual trajectories of young, cisgender gay men, from popular strata, in the metropolitan region of Rio de Janeiro, Brazil. Brazilian literature on violence against gay men generally focuses on the discrimination suffered by this population. However, the violence they are submitted to among family relationships due to their sexual orientation, or even their relationships known as "dating" or "hookup", is hardly discussed. This qualitative study used indepth interviews based on a semi-structured guide to discuss violence during the young gay men's affective-sexual trajectory. The results evidenced multiple faces of violence during childhood and adolescence in family relationships, spanning their affective-sexual relationships in adolescence and youth, including sexual, physical, psychological, and institutional violence. Support networks are limited, for example, to a few friends and access to blogs on the Internet. No health professional was cited as a helping source. There is a need to discuss the prevention of violence and discuss health promotion of this social group, expanding the perspective on the various contemporary ways of relating intimately.
\end{abstract}

Key words Youth, Violence, Trajectories, Masculinities, Gay
Resumo Este artigo aborda o fenômeno da violência nas trajetórias afetivo-sexuais de jovens gays cisgênero, pertencentes a camadas populares da região metropolitana do Rio de Janeiro, Brasil. A literatura brasileira sobre violência contra homens gays, geralmente, tem como foco a discriminação sofrida por esta população, mas pouco se problematiza a violência que eles sofrem nas relações familiares devido à sua orientação sexual, ou ainda, em suas relaçôes ditas como "namoro" ou "ficar". Com o objetivo de discutir a presença de violências durante a trajetória afetivo-sexual dos jovens, este estudo qualitativo realizou entrevistas em profundidade a partir de um roteiro semiestruturado. Os resultados mostraram que há múltiplas faces de violência que ocorrem durante a infância e adolescência nas relações familiares, perpassando nos seus relacionamentos afetivosexuais na adolescência e juventude, incluindo violências sexuais, físicas, psicológicas e institucionais. As redes de apoio dos jovens são limitadas, como exemplo, a poucos amigos e ao acesso de blogs na internet. Nenhum profissional de saúde foi citado pelos jovens como fonte de ajuda. Destacase também a necessidade de debater a prevenção da violência e promoção da saúde destes jovens, ampliando o olhar para as várias formas contemporâneas de se relacionar intimamente.

Palavras-chave Juventude, Violência, Trajetórias, Masculinidades, Gay 


\section{Introdução}

A violência nas relações afetivo-sexuais desconhece barreiras geográficas, estratos sociais, faixas etárias, religiões, etnias ou orientações sexuais, sendo resultado de uma combinação complexa de fatores históricos, culturais, econômicos, institucionais, interacionais e familiares, presente na vida de muitos jovens brasileiros ${ }^{1}$. Contudo, as relações conjugais, familiares e institucionais marcadas por violências são pautadas por silêncio e segredo, reforçando uma dicotomia entre o público e o privado e, apontando, muitas vezes para a banalização, naturalização e patologização das pessoas envolvidas ${ }^{2}$. Portanto, problematizar a violência nas relações afetivo-sexuais, principalmente dos mais jovens, torna-se uma tarefa fundamental e um desafio para o campo da saúde.

$\mathrm{Na}$ última década, assistimos à produção de estudos sobre violências que as pessoas LGBT enfrentam cotidianamente em diversos contextos, desde os espaços públicos até instituições como escolas e serviços de saúde ${ }^{3-5}$. Outros estudos analisam as experiências de violência contra adolescentes e jovens gays no processo de revelação de sua orientação sexual às famílias ${ }^{6-8}$. Contudo, nota-se que não se há contemplado as diversas formas de violência nas trajetórias afetivo-sexuais de jovens gays, nas relações com a família, namorados e "ficantes".

Este artigo buscou analisar as violências presentes na trajetória afetivo-sexual de homens jovens que se auto identificam como gays cisgênero, pertencentes a camadas populares no Rio de Janeiro: aquelas que acontecem nas relações familiares, como o abuso sexual e agressões no processo de revelação de sua orientação sexual; as que acontecem nas relações de "namoro" e "ficar" dos jovens, incluindo a violência sexual, física e psicológica; as violências institucionais presentes no atendimento em saúde. Buscou-se, ainda, identificar que redes de apoio foram utilizadas pelos jovens após sofrerem tais violências.

Entendemos violência como a ameaça ou o uso intencional da força ou do poder, englobando atos de agressão física, psicológica e sexual, fundamentados em concepções sociais e culturais de gênero9. Por sua vez, o gênero é compreendido por meio de sua constituição performativa, sendo produzido nas relações sociais, nas experimentações do viver, na articulação com o corpo, sexualidade, raça e classe social, atravessadas por relações de poder. A partir de uma discussão interseccional, reconhece-se a pluralidade das manifestações singulares e coletivas das subjeti- vidades, identificando qual categoria está sendo focada em certos regimes disciplinares, e como ela pode criar hierarquizações e exclusões ${ }^{10}$.

Portanto, analisar as relações de homens jovens gays cisgênero a partir de uma perspectiva interseccional implica um duplo processo: o entendimento do modo como se estruturam os processos assimétricos do eixo de dominação gênero (mesmo em relações entre pessoas do mesmo sexo) e, uma leitura que compagina o modo como o gênero se intersecta, que é reformulado e se articula com outras relações de privilégio e opressão ${ }^{10}$.

Nessa direção, surgem alguns questionamentos: quais são as distintas formas de violência que os jovens vivenciam durante suas trajetórias afetivo-sexuais? Como podemos refletir sobre violências, a partir de uma perspectiva interseccional, levando em consideração os marcadores de gênero, raça e classe? Com quem os jovens podem contar para lidar com tais experiências?

\section{Método}

Trata-se de um estudo qualitativo, cujo objetivo foi o de compreender a trajetória afetiva-sexual de 15 homens jovens gays cisgênero, pertencentes a camadas populares e moradores da região metropolitana da cidade do Rio de Janeiro.

Cumpriram-se todas as exigências de ética em pesquisa com vistas a garantir confidencialidade e segurança dos sujeitos. O critério de seleção foi ter idade entre 18 e 24 anos $^{11}$. Importante salientar que o primeiro autor deste artigo utilizou sua própria rede de contatos para aproximação com participantes iniciais da pesquisa, levando-se em consideração os desafios em pesquisar e "observar o familiar" ${ }^{\prime 2}$. As indicações posteriores aconteceram por meio da técnica "bola de neve"13. Dentre os 15 entrevistados, elencamos as narrativas de oito jovens que relataram situações de violências em suas trajetórias. As narrativas foram categorizadas a partir da análise temática ${ }^{14,15}$.

\section{Caracterização sociodemográfica dos entrevistados}

Conforme o Quadro 1, os jovens tinham idades entre 19 e 24 anos. Dos oito jovens em questão, quatro se declararam "negro". A maioria morava em favelas. Todos finalizaram o ensino médio em escolas públicas. Dois jovens cursavam ensino superior e um trabalhava em uma profissão que exigia curso superior. 
Quadro 1. Caracterização sociodemográfica.

\begin{tabular}{|c|c|c|c|c|c|c|c|}
\hline Sigla & Idade & $\begin{array}{c}\text { Cor/ } \\
\text { Raça }^{*}\end{array}$ & Onde morava & Escolaridade & Ocupação & Religião & $\begin{array}{c}\text { Características } \\
\text { corporais e de } \\
\text { gêneroo }^{* *}\end{array}$ \\
\hline RA & 22 & Negro & Favela & $\begin{array}{l}\text { Ensino superior } \\
\text { incompleto }\end{array}$ & $\begin{array}{l}\text { Não } \\
\text { trabalhava }\end{array}$ & Evangélico & "Só" passivo \\
\hline AS & 19 & Pardo & Favela & $\begin{array}{l}\text { Ensino médio } \\
\text { completo }\end{array}$ & "Uber eats" & $\begin{array}{l}\text { Sem } \\
\text { religião }\end{array}$ & $\begin{array}{l}\text { "Afeminado", "só" } \\
\text { passivo }\end{array}$ \\
\hline $\mathrm{VD}$ & 22 & Negro & Favela & $\begin{array}{l}\text { Ensino médio } \\
\text { completo }\end{array}$ & $\begin{array}{l}\text { Recursos } \\
\text { Humanos }\end{array}$ & Católico & $\begin{array}{l}\text { "Surdo-mudo, "só" } \\
\text { passivo }\end{array}$ \\
\hline VB & 22 & Branco & Favela & $\begin{array}{l}\text { Ensino médio } \\
\text { completo }\end{array}$ & $\begin{array}{l}\text { "Delivery de } \\
\text { Ifood" }\end{array}$ & $\begin{array}{l}\text { Sem } \\
\text { religião }\end{array}$ & $\begin{array}{l}\text { "Afeminado", } \\
\text { "gordinho", "só" passivo }\end{array}$ \\
\hline MS & 24 & Negro & $\begin{array}{l}\text { Bairro camada } \\
\text { popular }\end{array}$ & $\begin{array}{l}\text { Ensino médio } \\
\text { completo }\end{array}$ & $\begin{array}{l}\text { "Atendente no } \\
\text { shopping"* }\end{array}$ & Católico & $\begin{array}{l}\text { "Muito" magro, "só" } \\
\text { ativo }\end{array}$ \\
\hline $\mathrm{EF}$ & 23 & Branco & Favela & $\begin{array}{l}\text { Ensino superior } \\
\text { completo }\end{array}$ & $\begin{array}{l}\text { Professor em } \\
\text { uma ONG }\end{array}$ & Católico & "Muito" afeminado \\
\hline RT & 22 & Branco & $\begin{array}{l}\text { Bairro camada } \\
\text { popular }\end{array}$ & $\begin{array}{l}\text { Ensino médio } \\
\text { completo }\end{array}$ & $\begin{array}{l}\text { Atendente em } \\
\text { borracharia }\end{array}$ & Católico & $\begin{array}{l}\text { "Muito" afeminado e } \\
\text { magro }\end{array}$ \\
\hline $\mathrm{IM}$ & 23 & Negro & $\begin{array}{l}\text { Bairro camada } \\
\text { popular }\end{array}$ & $\begin{array}{l}\text { Ensino superior } \\
\text { incompleto }\end{array}$ & $\begin{array}{l}\text { Estágio em } \\
\text { uma ONG }\end{array}$ & Católico & $\begin{array}{l}\text { "Só" passivo, } \\
\text { "afeminado" }\end{array}$ \\
\hline
\end{tabular}

${ }^{\star}$ Categoria autodeclarada; ${ }^{\star \star}$ Categoria nativa. $\mathrm{N}=$ oito jovens participantes que participaram da pesquisa, identificados de acordo com a ordem da entrevista.

Fonte: Pesquisa empírica de doutorado do primeiro autor.

\section{Análise e discussão dos resultados}

Elencamos os seguintes temas para discussão: 1) Violência sexual na infância e adolescência; 2) Violência intrafamiliar no processo de revelação de se assumir gay; 3) Violência praticada por parceiro íntimo; 4) Violência nas relações com "ficantes": "stealth breeding". Por fim, um último tema denominado redes de apoio, circunscreve as formas de ajuda mencionadas pelos jovens no enfrentamento das situações de violência.

\section{Abuso sexual na infância e adolescência}

Três jovens relataram que sofreram abuso sexual na infância/adolescência. Entende-se por abuso sexual o ato ou jogo sexual, relação hetero ou homossexual cujo agressor é mais velho do que a criança/adolescente. Essas práticas são impostas à vítima pela violência física, ameaças ou indução de sua vontade ${ }^{16}$. O fenômeno do abuso sexual é encoberto por um muro de silêncio, do qual fazem parte, familiares, vizinhos/as e, algumas vezes, os/as próprios/as profissionais que atendem às vítimas ${ }^{17}$.

Segundos os jovens, a idade do abuso sexual ocorreu entre dez e 16 anos. Um abuso ocorreu durante três anos e os outros dois, em uma úni- ca ocasião. Os agressores faziam parte do círculo social e familiar das vítimas (primos e amigo do primo). Os jovens que sofreram abusos foram "passivos" no episódio e em nenhum caso, houve o uso de preservativo:

Eu fui abusado quando eu tinha dez anos. Fui criado com um primo. Ele devia ter uns 20 anos. Desde criancinha eu tinha sexo com ele. Demorei bastante pra entender o que tinha acontecido e é difícil porque eu acho que tinha gostado, não sei até que ponto eu me descobri com homossexualidade naquele momento. Parece que a sexualidade do surdo-mudo não existe. Não teve uso de camisinha nem nada. Fui só passivo com ele. Fiquei com esse primo por uns três anos. (VD, 22 anos).

Fui abusado na minha primeira vez. Quando eu tinha 13 anos eu fui na casa de uma prima minha e a gente se vestiu de mulher. Tava só eu, ela e o meu primo, irmão dela. Minha prima disse que ia no mercado e eu fiquei lá. Eu saí do quarto, mas tava vestido de mulher. Meu primo me viu e começou a me zoar, me chamando de viadinho $e$ que eu tinha que aprender a virar homem. Eu falei que era só uma brincadeira, mas ele nem deu bola. Ele me agarrou pelos braços, disse que se eu gritasse ou fizesse alguma coisa, ele ia contar pra todo mundo que eu me vestia de mulher. Ele tinha uns 20 anos! Só lembro que ele me agarrou e me colocou de 
bruços. Falou pra eu ficar quieto e não gritar. Não durou nem cinco minutos. Perdi a virgindade ali. Fiquei sem reação na hora, depois que ele acabou eu comecei a chorar. Ele falou pra eu calar a boca senão a irmã dele ia desconfiar [...]. Foi sem camisinha. Ela chegou e eu tava chorando, mas não falei nada. Falei que o brinco da mãe dela tava me machucando e pra eu tirar. Fui embora e esqueci essa história. (EF, 23 anos).

Com 16 anos eu tava jogando videogame com um primo e um amigo dele. Aí rolou um papo sobre gozar, fazer troca-troca. Eu falei que já tinha chupado um menino. Мeu primo perguntou se eu não queria chupar ele, aí eu falei que sim. Aí comecei a chupar ele e depois de uns minutos, chupei o amigo dele. Мeu primo tirou minha bermuda e disse que ia meter em mim, que eu era um viadinho e que ia acabar gostando. Eu falei que não tava a fim, que era virgem. Mas o amigo dele me segurou de bruços e foi. Tipo, fui abusado mesmo. Aí depois o meu primo segurou meus braços e o amigo dele que abusou. Doeu muito e eu fiquei sangrando. E foi tudo sem amisinha'. Depois eu comecei a chorar e eles foram embora [...] Eles tinham 23 anos! (RT, 22 anos).

Para além da pouca idade comum de todos os que sofreram os abusos, bem como a diferença de idade entre os envolvidos, os marcadores sociais também merecem destaque.

Na primeira narrativa, VD22 relatou que era "surdo-mudo" desde seu nascimento. No relato sobre sua primeira experiência sexual, ele considerou a relação como abusiva, que durou três anos. As relações ocorreram no ambiente familiar (com seu primo mais velho), sem a compreensão primeira do entrevistado: "Eu não tive culpa. Demorei bastante pra entender o que tinha acontecido!".

A partir de uma perspectiva interseccional, salienta-se que o jovem vive uma condição de vulnerabilidade social e sexual. Ele não tinha para quem comunicar sobre o que estava vivenciando, o que indica um certo isolamento pela sua deficiência. As relações sexuais ocorridas na infância são entendidas como um marco da sua "condição gay": "Não sei até que ponto eu me descobri com homossexualidade naquele momento". Ou seja, o ato sexual parece ser estabelecido como essencial no processo de construção da sua identidade sexual, constituindo-se como um marco subjetivo importante. Para este jovem, existe uma relação direta entre o primeiro ato sexual e a vivência (atual) de ser gay, como se ele tivesse "pegado a homossexualidade".

Nessa direção, a relação entre ser gay e deficiência anuncia discussões teóricas importantes sobre sexualidade. Autores ${ }^{18}$ citam que esses sujeitos se constituem a partir de duas (ou mais) categorias de pertencimento que são socialmente construídas em um espaço de menor valia.

Ainda segundo sua narrativa, "a sexualidade do surdo-mudo parece que não existe", o que parece acarretar numa dupla invisibilidade social entre ser gay e deficiente. Percebe-se que a deficiência é tomada como característica principal do sujeito, não podendo assim, existir sua sexualidade. Considera-se que frente à deficiência, soma-se outras discriminações como as de gênero, orientação sexual, raça e classe social.

Nessa direção, pessoas com deficiência são vulneráveis à violência sexual por dois fatores: primeiro, por serem invisíveis socialmente; e, segundo, pela consciência do agressor de que o risco de denúncia do abuso é praticamente inexistente, pois com frequência a pessoa com deficiência estará isolada e sem apoio (familiar e escolar) ${ }^{19}$. Portanto, no caso dos surdos-mudos, é importante ressaltar que a incompatibilidade linguística com a comunidade ouvinte majoritária e a não aquisição da língua de sinais favorecem a emergência de contextos abusivos e geram situações complexas de vulnerabilidade.

Já outros dois jovens, EF23 e RT22, se consideravam "muito afeminados desde criancinhas". Em comum, nota-se uma mesma frase dita pelos agressores: "Você é viadinho, tem que aprender a virar homem"; "Você é viadinho, vai acabar gostando (do abuso)". Tais frases remetem à hierarquia entre o "abusador-ativo-homem" e a "vítima-passiva-mulher". Na literatura, tal abuso é denominado como "estupro corretivo"20-22. Comumente referido às mulheres lésbicas, tal prática é cometida sob pretexto de "curar as suas orientações sexuais e identidades de gênero" 22 .

No caso dos jovens entrevistados, ser "afeminado" faz o abusador entender que tal abuso pode ser justificado como forma de "lição", como se o abuso fosse "corrigir" sua "não heterossexualidade" e ensinasse o jovem a "ser heterossexual". O abuso perpassa apenas pela sua expressão de gênero "afeminada". Nessa direção, a heteronormatividade torna-se uma faceta importante para pensar a violência como sanção e como forma pedagógica de correção de uma expressão de gênero ${ }^{23}$.

Em síntese, o abuso sexual e o estupro corretivo são baseados na inconformidade do abusador com a sexualidade das vítimas, seja ela mulher ou homem. Trata-se da combinação do machismo com homofobia. $\mathrm{O}$ abusador considera a sexualidade da vítima uma transgressão à regra moral, biológica e social, e a ideia é "curá-lo"24. 
Assim, a heteronormatividade aliada ao modelo de masculinidade hegemônica ${ }^{25}$, que estabelece cultural e historicamente a valorização da masculinidade heterossexual, configura relações de poder entre homens e mulheres, e entre homens que escapam de padrões de masculinidade vigentes, refletindo na violência sexual frente a homens gays e "afeminados".

\section{Violência intrafamiliar no processo de revelação de se assumir gay}

As famílias, em particular pai e mãe, tiveram reações negativas frente à revelação da orientação sexual dos jovens, mostrando pouco apoio e o uso de violência:

Meu pai uma vez achou camisinha no meu quarto e me pressionou pra saber com quem eu tava transando. Aí eu acabei contando que levei um amigo pra casa. Foi horrível! Ele me bateu, disse que não criou um filho pra ser viado. Minha mãe tava em casa chorando, pedindo pra ele não me bater. No outro dia ele me falou que já que eu era gay, pelo menos pra ser ativo! Depois que eu contei, eles me proibiram de sair também. Não podia ver meus amigos, nem sair de casa. Como se ficar em casa fosse fazer eu deixar de ser gay! (MS, 24 anos).

Eu decidi contar porque não via mais motivo pra esconder. Não pensei que meus pais iam reagir dessa forma. Meu pai me bateu muito, muito mesmo. Não gosto nem de lembrar. Aí no outro dia minha mãe falou que era melhor eu morar com a minha avó, que não dava mais pra gente morar junto porque eu era gay e eles não iam aceitar um gay dentro de casa. Eu me mudei e até hoje moro com a minha avó. (RT, 22 anos).

Eu contei primeiro pra minha mãe. Falei que tava namorando e falei o nome dele. Ela chorou, disse que era só uma fase e eu precisava reencontrar Deus. Ela falou pra eu parar de escutar umas cantoras e eu não jogar mais vôlei. Mas depois de uns três meses, acho que ela começou a aceitar. Depois ela disse que ficou preocupada e que pra eu não contar pro meu pai, que ela tinha medo do que ele podia fazer (RA, 22 anos).

As reações violentas, como xingamentos, agressões físicas e expulsão de casa, além de controle e vigilância, fizeram parte do processo de "se assumir” para a família. Tais reações se pautam na heteronormatividade, como um dispositivo regulador da sexualidade, incluindo visões morais e religiosas negativas sobre ser gay, em que a estrutura social e sexual que se fundamenta no dualismo hetero/homossexual, de forma a priorizar a heterossexualidade por meio de um dis- positivo que a naturaliza e, ao mesmo tempo, a torna compulsória ${ }^{26}$, fazendo com que a família se distancie dos jovens no momento de afirmação de sua sexualidade.

Este distanciamento também reforça o modelo hegemônico de masculinidade, que estabelece a valorização da masculinidade heterossexual, subordinando aqueles que desviam dos padrões desta masculinidade ${ }^{27}$. Diante disso, a violência, o preconceito e a discriminação estabelecem uma relação de manutenção desta masculinidade, que precisa ser reafirmada e controlada.

Nesse sentido, as diversas mudanças ocorridas nas últimas décadas não foram capazes de desconstruir ou eliminar o "armário", entendido como um dispositivo de manutenção do segredo da sexualidade gay, nas quais os sujeitos irão negociar constantemente sua visibilidade e a aceitabilidade de seus desejos ${ }^{28}$.

\section{Violência praticada por parceiro íntimo}

Um jovem relatou que sofreu violência sexual pelo ex-namorado. Outro narrou momentos em que o relacionamento abusivo foi permeado de violências psicológicas e simbólicas, incluindo o racismo e gordofobia.

Compreendemos a violência sexual como ato ou tentativa do ato sexual, investidas ou comentários sexuais indesejáveis contra a sexualidade de uma pessoa a partir da coerção $0^{9}$. Já a violência psicológica compreende formas de rejeição, depreciação, discriminação, e proibição de atividades por quem a pratica, e atingindo emocional e psiquicamente quem sofre ${ }^{29}$. A violência simbólica é demarcada como "uma violência que se exerce com a cumplicidade tácita daqueles que a sofrem e também, frequentemente, daqueles que a exercem na medida em que uns e outros são inconsciente de a exercer ou a sofrer"30.

De acordo com os jovens:

Eu namorei quando tinha 17 anos, ele 22. Foi um namoro muito bom, durou um ano. Mas no final começou a ficar bem ruim, descobri traições. Foi um ano difícil, eu tava brigando muito com a minha mãe, engordei bastante, tinha reprovado na escola. Ele ficava falando que tava ficando feio $e$ gordo, isso foi minando minha autoestima. A gente foi se encontrando menos, parando de transar. Ele ficou me traindo, 'me chamava de baleia e feio'. Com muita dificuldade, eu terminei. Depois de dois meses ele pediu pra gente conversar. Ele veio com papo pra gente voltar, mas eu disse que não. Ele começou a ser agressivo, aí ele me segurou e me estuprou. Não durou nem cinco minutos, não faço 
questão de lembrar nada disso. Ele segurou meu braço e o corpo dele tava em cima do meu, eu tentei resistir, mas ele era mais forte que eu e eu congelei. Depois eu só catei minhas coisas e fui embora. Só posso dizer que foi a pior coisa minha vida e fiquei três anos sem fazer sexo depois disso. (VB, 22 anos).

Namorei um menino que toda hora falava que ia me trocar por um garoto mais branco, ele namorava um menino antes de mim que era branco $e$ tinha olho claro. Ele jogava na minha cara que eu não era da cor do ex dele. Ele era loiro, era forte e eu não. Ele ficava me diminuindo dizendo que esse ex era mais branco que eu. Dizia que o ex foi apresentado pra família dele, mas eu não ia ser porque não era branco o suficiente. Ele fez um contrato pra eu assinar, que eu nunca ia terminar com ele. E eu assinei. Eu não saía, não via meus amigos, só ficava com ele, ele que decidia tudo se a gente ia se ver no final de semana. (IM, 23 anos).

As violências sexual, psicológica e simbólica praticadas por parceiro íntimo (VPI) são relatadas de diversas formas durante as trajetórias. A VPI é um abuso continuado sobre um indivíduo com o qual um sujeito conserva ou conservou um relacionamento íntimo, seja um namoro, uma união ou um casamento entre homo ou heterossexuais ${ }^{1}$. Estudos recentes têm debatido a presença de violências nos relacionamentos entre casais gays ${ }^{31-34}$. Esses trabalhos salientam que a invisibilidade da VPI entre os casais gays masculinos é reforçada pelo receio da patologização que esse grupo percebe a seu respeito, em consequência do estigma vivido na nossa sociedade ${ }^{33}$. Além disso, o preconceito favorece a sua ocultação, pois as vítimas de VPI temem denunciar receando sofrer mais humilhação, discriminação e homofobia ${ }^{31}$.

É preciso ainda levar em consideração que o namoro entre homens é muitas vezes visto como uma "relação entre iguais" em que não há assimetrias de poder. Os próprios agressores utilizam com regularidade este mito, para justificar suas condutas violentas ${ }^{34}$. Outro fator importante é que há uma ideia de que "namoro não é lugar de violência"35, ocorrendo apenas em relações mais estáveis e duradouras, situação que exclui o "namoro" e "ficar", comuns entre adolescentes e jovens ${ }^{35}$.

\section{Violência nas relações com "ficantes": "stealth breeding"}

Um dos entrevistados relatou outro tipo de violência numa relação sexual episódica: a remo- ção da camisinha pelo parceiro sem o seu consentimento com um "ficante":

Já teve vezes que eu fui encontrar com alguns caras, mas sempre deixei bem claro que só rolava com camisinha. Mas acho que essas coisas de camisinha são mais difíceis pro passivo. Já aconteceu duas vezes de os caras tirarem a camisinha, $e$ tipo, às vezes tô de costas, não tô vendo o que ele tá fazendo, e nem sempre consigo sentir que tá sem. Teve uma vez que eu fui pra um hotel chique transar com um cara, ele gozou dentro de mim e só depois que acabou que eu vi e fiquei sabendo! Sendo passivo é mais difícil de você controlar a camisinha! (AS, 22 anos).

A prática conhecida como "stealthing" é mais debatida nos estudos sobre relações heterossexuais. Estudos recentes ${ }^{36-38}$ citam que a prática é comum entre jovens heterossexuais, sexualmente ativos, sendo um debate controverso. Embora para muitas mulheres pareça óbvio que a prática é abusiva, outras a consideram como um "sexo ruim". Já para alguns homens, muitos acreditam que isso é um "direito natural" deles e disseminam a prática pela internet, dando dicas de como remover o preservativo sem a parceira perceber ${ }^{36}$. Tais homens enraízam suas ações em misoginia e na crença da supremacia sexual masculina frequentemente citando o direito de homem de "espalhar sua semente" 38 .

Contudo, o ato de remover a camisinha durante a relação sexual sem o consentimento do parceiro não é uma prática exclusiva de relações heterossexuais. Com uma denominação distinta, a remoção da camisinha sem o consentimento do parceiro é denominada como "stealth breeding", conforme alguns estudos internacionais ${ }^{39-41}$.

A prática é considerada como uma forma de sexo sem preservativo entre homens, conhecido como bareback. Contudo, a prática se caracteriza pela remoção não consensual do preservativo por parte do ativo da relação. Interessante destacar que apesar de uma crescente literatura sobre a prática bareback nos últimos dez anos ${ }^{42,43}$, estudos sobre "stealth breeding" são inexistentes no Brasil.

AS22, morador de uma favela, foi encontrar seu parceiro em um hotel "caro e chique", perto de sua casa. O jovem salientou que se sentia "fetichizado" por ser morador de favela, já que muitos homens pensavam que ele era traficante de drogas ou ainda, "que só ficava com bandidos". Portanto, é importante considerar como se entrecruzam os diferentes marcadores de pertencimento nesse cenário. $\mathrm{O}$ encontro entre um rapaz morador de favela, pardo e "só passivo", e outro rapaz, morador "do asfalto", de classe social privilegiada 
e "ativo", coloca em xeque relações de opressão, em que o poder e a dominação, por parte do jovem de classe social alta, podem provocar uma ausência de negociação do não uso da camisinha. Trata-se de um olhar que aborda os efeitos coercitivos das relações de poder, mostrando que a relação entre dois homens pode ser bastante assimétrica. Portanto, os eixos de poder estabelecidos pelo patriarcado, pelo racismo e pela luta de classes se cruzam como avenidas em que o fluxo do tráfego define a multiplicidade de opressões às quais uma pessoa está submetida ${ }^{44}$.

Problematizar a remoção da camisinha sem o consentimento do parceiro é fundamental para o debate da vivência de uma sexualidade saudável. O "stealth breeding" transforma uma relação sexual "consensual" em "não consensual", sendo que as vítimas, por vezes, sequer percebem a conduta do parceiro durante o ato. Nessa direção, torna-se imprescindível considerar a prática como um caso de violência.

Como desdobramento do ocorrido, o jovem foi a uma unidade de saúde buscar a Profilaxia Pós-Exposição (PEP), uma tecnologia de prevenção que consiste no uso de antirretrovirais por 28 dias, iniciando em até 72 horas após a possível exposição sexual ao HIV, disponibilizada pelo SUS ${ }^{45}$. Ao buscar a PEP, se deparou com o desrespeito da profissional de saúde, configurando-se uma violência institucional ${ }^{46}$. Em relação ao atendimento:

Não foi muito bom não. Eu não tive dificuldade de conseguir os remédios, mas as enfermeiras - acho que eram enfermeiras -, foram um pouco, 'meio que julgadoras', sabe? A primeira pergunta que ela fez foi se eu tinha sido irresponsável e feito sexo sem camisinha, aí eu não queria contar toda a história do cara, que eu não fiz por escolha, e só falei que sim. Aí com uma cara muito feia, ela perguntou se eu me relacionava com homem ou com mulher, aí falei que com homem [...] Aí, ela com uma cara bem debochada, disse: Tinha que ser, né! [...] Aí é óbvio que ela tava achando que eu era um viado que transava sem camisinha e era irresponsável e tava indo lá tomar os remédios. (AS, 22 anos, grifos nossos).

Como pode ser visto na narrativa, a obtenção da PEP ainda apresenta barreiras como discriminação para quem a busca. Autores/as ${ }^{45,47,48}$, sinalizam que apesar da importância de tal estratégia de profilaxia, deve-se considerar a persistência do julgamento moral e estigma em torno da sexualidade, bem como o cenário de conservadorismo crescente brasileiro. Portanto, os desafios para a oferta de prevenção nos serviços de saúde devem considerar a perspectiva individual de profissionais de saúde e usuários, bem como a dimensão organizacional e estrutural dos serviços.

\section{Redes de apoio}

Compreende-se a rede de apoio social como o conjunto de relações que um sujeito percebe como significativas em momentos de estresse, como situações de violência ${ }^{49}$. Desse modo, considera-se que a rede de apoio social, dependendo de como estão constituídos e de sua disponibilidade e efetividade no cotidiano, são capazes de fortalecer laços de proteção para a garantia dos direitos de adolescentes e jovens, bem como responder melhor à complexidade das demandas trazidas pela violência perpetrada contra jovens gays $^{50}$. Os entrevistados narraram:

Quando fui estuprado, não fiz terapia, mas li muita coisa na internet. Li que a pessoa que é abusada tende a se culpar, e muita gente relata que tinha medo e vergonha de denunciar. Tem um site que me chamou bastante atenção, eu não lembro o nome, que falava de abuso de quem era gay adulto, mas assim, tinha muita coisa de coroinha lá, $e$ gente que não queria ser gay, ai meio que culpavam ser gay porque tinham sofrido abuso quando criança. Era pesado, mas lendo tudo me fez perceber que eu não fui abusado quando criança sabe, eu não queria entender o porquê eu era gay e colocar a culpa naquilo, só queria entender porque eu deixei aquilo acontecer, que na verdade, não foi culpa minha. Mas aí eu lia e via que elas passavam por isso, que existe muito estupro em relacionamento. Mas é isso, me fez bem ler coisas de quem já tinha passado por esse tipo de abuso no namoro, apesar de que eram todas mulheres, não li em nenhum lugar sobre estupro no namoro entre homens. (VB, 22 anos).

Eu faço parte de um grupo do Facebook de apoio pra quem é surdo ou surdo-mudo que me ajuda bastante nesse sentido, vi que muitos surdo-mudos passaram pela mesma coisa, de abuso quando pequeno. Vi também que é comum o abuso começar na família. Vi que é comum ninguém conversar com a gente sobre sexo nem nada. Nunca falei pra minha mãe nem pra nenhum amigo, sempre tive vergonha. (VD, 22 anos).

Acho que todo apoio que eu tive, foi na internet. Li muitos blogs depois do abuso e sempre olhei online alguma coisa que tinha curiosidade. Não quis contar pra ninguém que tava vestido de mulher quando fui abusado, sempre tive vergonha. Li na internet que muitas mulheres sofreram abuso por conhecidos. Quando eu lia os depoimentos, me 
identificava porque conseguia ver que outras pessoas tinham passado pela mesma coisa que eu. (EF, 23 anos).

Em relação às redes de apoio, percebe-se que os jovens não foram à delegacia por medo e vergonha de denunciar o parceiro, não contaram para a família sobre o ocorrido, e quase nenhum amigo soube, e tampouco tiveram algum acompanhamento psicológico. Os jovens leram blogs na internet como forma de acolhimento e elaboração do ocorrido, indicando uma rede de apoio institucional e pessoal limitada para as suas necessidades.

Em uma geração de adolescentes e jovens que nasceram conectados à internet $t^{51}$, a internet acaba sendo uma ferramenta bastante destacada em todas as entrevistas. Apesar da limitação, os blogs viabilizam um contato, que mesmo distante, parece ser íntimo e próximo, em que os jovens perceberam "de perto" que outras pessoas (em sua maioria, mulheres) já haviam passado pela mesma experiência. Dessa forma, a internet apareceu como um lugar de acolhimento, algo que eles não encontraram fora do "mundo virtual". Cabe sugerir que a esta "cultura do compartilhamento de vivências de violência", tem suas características amplificadas por sua articulação com a cibercultura, sendo a expressão da aspiração de um laço social, centrada em torno de um interesse em comum e sobre processos abertos de colaboração $0^{52}$.

Este contato torna-se ainda mais importante para jovens de camadas populares, que sem condição financeira, se limitam ao uso da internet para se sentirem amparados. Os jovens consideram este espaço "protegido pelo anonimato", sem a necessidade de grandes exposições.

Destaca-se ainda que todos os jovens relataram que suas experiências eram similares a experiências de diversas mulheres no Brasil, o que pode indicar em uma invisibilidade na ocorrência de violências entre/contra homens na esfera da sexualidade. Portanto, tal invisibilidade acarreta a importância da rede de apoio social como fator de proteção frente às vulnerabilidades a que crianças, adolescentes e jovens gays estão expostos. Ao se perceberem "diferentes" de seus pares, podem ter pensamentos negativos a respeito de si mesmos, internalizando a homofobia e muitas vezes se culpabilizam pela situação de violência ocorrida ${ }^{8}$.

Como mostrado na presente pesquisa, a falta de apoio social pode ser associada a maior solidão após a ocorrência de violências na infância ou em um relacionamento durante a juventude. Ainda, este estudo também pode indicar que uma rede social composta por um grupo pequeno de colegas e sem a presença da família, parece ser consequência de experiências de homofobia e discriminação presentes em nossa sociedade.

\section{Considerações finais}

O fenômeno da violência é complexo e multicausal e representa uma grave violação de direitos humanos. No entanto, carecemos de mais estudos sobre as dinâmicas das violências a que jovens gays cisgênero estão expostos. Essas violências presentes nas relações de intimidade, incluindo a família e parceiros íntimos, expõem o grau de preconceito, discriminação e estigmas decorrentes da orientação sexual e/ou expressões de gênero dissidentes da heteronormatividade e de modelos tradicionais de masculinidade.

A partir de uma perspectiva interseccional, chama a atenção o entrecruzamento de marcadores sociais reconhecidamente oprimidos e subalternizados na sociedade brasileira como os de classe social, raça, deficiência ou expressões de gênero consideradas femininas e que colocam esses jovens em situações de maior vulnerabilidade.

Vale ressaltar que essas inúmeras faces de violências e sua articulação com os marcadores sociais da diferença não se restringem ao âmbito das relações interpessoais, mas também estão presentes na condução de profissionais no âmbito da saúde apontado no caso da violência institucional. Mais uma vez o preconceito em relação à homossexualidade se faz presente. Nesse sentido, não surpreende que esses jovens tenham uma rede de apoio empobrecida e se valham de blogs e outras mídias digitais em busca de ajuda e de compartilhamento de experiências.

Destacamos a necessidade de delinear políticas públicas capazes fomentar práticas de cuidado a adolescentes e jovens gays cisgênero, constituindo um suporte no enfrentamento de situações de violência e das vulnerabilidades a que são continuamente expostos em suas relações íntimas. Compreendemos que uma rede de apoio social multisetorial é essencial para o enfrentamento da violência, minimizando assim a vulnerabilidade à violência e, consequentemente, aumentando os fatores de proteção na sua saúde e bem-estar destes jovens. 


\section{Colaboradores}

W Ferrari foi responsável pela revisão da literatura, coleta, organização e análise do material empírico da pesquisa e revisão final do texto. MAF Nascimento foi responsável pela revisão da literatura, análise do material empírico da pesquisa e organização conjunta na discussão dos dados e revisão final do artigo. C Nogueira e L Rodrigues foram responsáveis pela organização conjunta na discussão dos dados e revisão final do artigo.

\section{Referências}

1. Minayo MCS, Assis SG, Njaine K, organizadores. Amor e violência: um paradoxo das relações de namoro e do "ficar" entre jovens brasileiros. Rio de Janeiro: Editora Fiocruz; 2011.

2. Nascimento M. Masculinidade, Juventude e Violência contra a Mulher: articulando saberes, práticas e políticas. In: Blay E, organizadora. Feminismos e Masculinidades: novos caminhos para enfrentar a violência contra a mulher. São Paulo: Cultura Acadêmica; 2014. p. 211-225.

3. Apostolo MVA, Moscheta MS, Souza LV. Discursos e posicionamentos em um encontro de diálogo sobre violência a LGBTs. Psicol USP 2017; 28(2):266-275.

4. Soares L. Cuidado em saúde e transfobia: percepções de travestis e transexuais de duas regiões do Rio de Janeiro: Maré e Cidade de Deus, sobre os serviços de saúde [dissertação]. Rio de Janeiro: ENSP/Fiocruz; 2018.

5. Souza LV, Moscheta MS, Scorsolini-Comin F. Grupos de Conversações Públicas como Recurso contra a Violência à População LGBT. Paideia 2019; 29:e2905.

6. Albuquerque GA, Garcia CL, Alves MJH, Queiroz CMHT, Adami F. Homossexualidade e o direito à saúde: um desafio para as políticas públicas de saúde no Brasil. Saude Debate 2013; 38(98):516-524.

7. Soliva T, Silva Jr JB. Entre revelar e esconder: pais e filhos em face da descoberta da homossexualidade. Sex Salud Soc 2014; 17:124-148.

8. Braga IF, Oliveira WA, Silva JL, Mello FCM, Silva MAI. Violência familiar contra adolescentes e jovens gays e lésbicas: um estudo qualitativo. Rev Bras Enferm 2018; 71(Supl. 3):1220-1227.

9. Krug EG, Dahlberg LL, Mercy JA, Zwi AB, Lozano R, editores. World Report on violence and health. Geneva: WHO; 2002.

10. Nogueira C. Interseccionalidade e psicologia feminista. Salvador: Editora Devires; 2017.

11. World Health Organization (WHO). What about boys? A literature review on the health and development of adolescent boys. Geneva: WHO; 2000.

12. Velho G. Observando o familiar. In: Velho G. Individualismo e cultura: notas para um a antropologia da sociedade contemporânea. Rio de Janeiro: Jorge Zahar; 1987.

13. Turato ER. Tratado da Metodologia da Pesquisa Clínico-Qualitativa. Petrópolis: Vozes; 2003.

14. Braun V, Clarke V. Using thematic analysis in psychology. Quali Res Psychol 2006; 3(2):77-101.

15. Braun V, Clarke V, Weate P. Using thematic analysis in sport and exercise research. In: Smith B, Sparkes AC, editores. Routledge handbook of qualitative research in sport and exercise. Londres: Routledge; 2016. p. 191205.

16. Cara AT, Neme CMB. Estudo documental de crianças vítimas de violência sexual: avaliação dos indicadores de comprometimento emocional segundo Koppitz. Acad Paul Psicol 2016; 36(91):383-399.

17. Braun S. A violência sexual infantil na família: Do silêncio à revelação do segredo. Porto Alegre: Age; 2002.

18. Maia ACB, Ribeiro PRM. Desfazendo mitos para minimizar o preconceito sobre a sexualidade de pessoas com deficiências. Rev Bras Educ Espec 2010; 16(2):159-176. 
19. Ferreira WB. Vulnerabilidade à violência sexual no contexto da escola inclusiva: Reflexão sobre a invisibilidade da pessoa como deficiência. Rev Iberoam Calidad Eficacia Cambio Educ 2008; 6(2):120-136.

20. Sánchez FL. Homossexualidade e Família: Novas Estruturas. Porto Alegre: Editora Artmed, Editora AS; 2009.

21. Contreras JM, Bott S, Guedes A, Dartnall E. Violência sexual na América Latina e no Caribe: uma análise de dados secundários. Iniciativa de Pesquisa sobre Violência Sexual; 2010.

22. Campos CH, Machado LZ, Nunes JK, Silva AR. Cultura do estupro ou cultura antiestupro? Rev Direito GV 2017; 13(3):981-1006.

23. Carrara S. Políticas e direitos sexuais no Brasil contemporâneo. Bagoas 2010; 5:131-147.

24. Cavalcanti VRS, Santos BC, Lacerda LA. Estupro corretivo na América Latina: analisando a violência sexual contra pessoas LGBTTQIS. In: ME Calazans, ES Piñeiro, organizadoras. As desigualdades de gênero e raça na América Latina no século XXI. Porto Alegre: Editora Fiocruz; 2019. p. 233-262.

25. Connell R. Gender and Power. Cambridge: Polity Press; 1987.

26. Butler J. Problemas de gênero. Rio de Janeiro: Civilização Brasileira; 2003.

27. Connell R. Masculinities. Berkeley: University of California Press; 1995.

28. Saggese G. Quando o Armário é Aberto: visibilidade e estratégias de manipulação no coming out de homens homossexuais [dissertação]. Rio de Janeiro: Universidade do Estado do Rio de Janeiro; 2019.

29. Signorini H, Brandão E. Psicologia jurídica no Brasil. Rio de Janeiro: Nau; 2004.

30. Bourdieu P. Sobre a televisão. Paris: Liber-Raison d'Agir; 1996.

31. Cezario ACF, Fonseca DS, Lopes NC, Lourenço LM. Violência entre parceiros íntimos: uma comparação dos índices em relacionamentos hetero e homossexuais. Temas Psicol 2015; 23(3):565-575.

32. Moreira AM. A violência por parceiro íntimo em casais homoafetivos masculinos: visibilizando o fenômeno [dissertação]. Belo Horizonte: Universidade Federal de Minas Gerais; 2017.

33. Santos AM, Caridade S. Violência nas relações íntimas entre parceiros do mesmo sexo: estudo de prevalência. Temas Psicol 2017; 25(3):1357-1371.

34. Elísio R, Neves S, Paulos R. A violência no namoro em casais do mesmo sexo: discursos de homens gays. Rev Critica Cien Soc 2018; 117:47-72.

35. Gomes R. Invisibilidade da violência nas relações sexuais afetivas. In Minayo MSC, Assis SG, Njaine K. Amor e violência: Um paradoxo das relações de namoro $e$ do 'ficar' entre jovens brasileiros. Rio de Janeiro: Editora Fiocruz; 2011. p. 141-151.

36. Soares R. Retirar o preservativo durante o ato sexual constitui crime? Stealthing analisado à luz do Código Penal Brasileiro [Internet]. JusBrasil; 2017 [acessado 2020 mar 10]. Disponível em: https://renansoares7127.jusbrasil.com.br/artigos/455520761/retirar-o -preservativo-durante-o-ato-sexual-constitui-crime.
37. Lima JD. Sobre o "stealthing", a prática de retirar a camisinha durante a relação sem consentimento da parceira [Internet]. 2017 [acessado 2020 mar 10]. Disponível em: https://arquivoradical.wordpress. com/2017/05/09/sobre-o-stealthing-a-pratica-de-retirar-a-camisinha-durante-a-relacao-sem-consentimento-da-parceira/.

38. Nunes DH, Lehfeld LS. Stealthing: aspectos acerca da violência de gênero e afronta aos direitos fundamentais. Rev Libertas Direito UFOP 2018; 3(2):93-108.

39. Brennan J. Stealth breeding: bareback without consent. Psychol Sex 2017; 8(4):318-333.

40. Ebrahim S. I'm Not Sure This Is Rape, But: An Exposition of the Stealthing Trend. SAGE Open 2019; 9(2):e2158244019842201.

41. Latimer RL, Vodstrcil LA, Fairley CK, Cornelisse VJ, Chow EPF, Read TRH. Non-consensual condom removal, reported by patients at a sexual health clinic in Melbourne. Plos One 2018; 13(12):e0209779.

42. Barreto VHS. Risco, prazer e cuidado: técnicas de si nos limites da sexualidade. Ava Rev Antropol 2017; 31:119-142.

43. Bezerra VP, Giacomini S. Sem capa: notas sobre o trabalho de campo de uma etnografia sobre o sexo bareback entre homens na cidade do Rio de Janeiro. Teoria Cult 2020; 15:16-31.

44. Crenshaw K. Documento para o Encontro de Especialistas em Aspectos da Discriminação Racial Relativos ao Gênero. Estud Fem 2002; 10:171-188.

45. Maksud I, Fernandes NM, Filgueiras SL. Tecnologias de Prevenção do HIV e desafios para os serviços de saúde. Rev Bras Epidemiol 2015; 18(Supl. 1):104-119.

46. Faleiros VP. Uma experiência de supervisão na área psicossocial: desafios teórico-práticos. Rev Katálysis 2009; 12(2):258-267.

47. Bezerra VP. Cenários políticos brasileiros, conquistas e desafios para as políticas públicas de saúde no contexto da prevenção e tratamento do HIV/AIDS e ISTs. O social em questão 2019; 45:43-66.

48. Monteiro S, Brigeiro M. Prevenção do HIV/Aids em municípios da Baixada Fluminense, Rio de Janeiro, Brasil: hiatos entre a política global atual e as respostas locais. Interface (Botucatu) 2019; 23:e180410.

49. Sluzki C. A rede social na prática sistêmica: Alternativas terapêuticas. São Paulo: Casa do Psicólogo; 1997.

50. Deslandes SF. Redes de proteção social e redes sociais: uma práxis integradora. In: Violência faz mal à saúde. Brasília: MS; 2004.

51. Oliveira GM. Geração Z: Uma nova forma de sociedade. Ijuí: UNIJUÍ; 2010.

52. Lévy P. Cibercultura. São Paulo: Editora 34; 1999.

Artigo apresentado em 30/04/2020

Aprovado em 31/03/2021

Versão final apresentada em 02/04/2021

Editores chefes: Romeu Gomes, Antônio Augusto Moura da Silva 